\title{
A randomized, controlled comparison of electrical versus pharmacological cardioversion for emergency department patients with acute atrial flutter
}

\author{
Ian G. Stiell ${ }^{1,2} \cdot$ Marco L. A. Sivilotti $^{3} \cdot$ Monica Taljaard $^{4} \cdot$ David Birnie $^{5} \cdot$ Alain Vadeboncoeur $^{6}$. \\ Corinne M. Hohl ${ }^{7}$. Andrew D. McRae ${ }^{8} \cdot$ Judy Morris $^{10} \cdot$ Eric Mercier $^{12} \cdot$ Laurent Macle $^{6} \cdot$ Robert J. Brison $^{3}$. \\ Venkatesh Thiruganasambandamoorthy ${ }^{1,2}$. Brian H. Rowe ${ }^{9}$. Bjug Borgundvaag ${ }^{11}$. Catherine M. Clement ${ }^{13}$. \\ Jennifer Brinkhurst ${ }^{13}$. Erica Brown ${ }^{13} \cdot$ Marie-Joe Nemnom $^{13} \cdot$ George A. Wells $^{14}$. Jeffrey J. Perry ${ }^{1,2}$
}

Received: 10 August 2020 / Accepted: 9 December 2020 / Published online: 18 January 2021

( ) The Author(s), under exclusive licence to Canadian Association of Emergency Physicians (CAEP)/ Association Canadienne de Médecine d'Urgence (ACMU) 2021

\begin{abstract}
Background Acute atrial flutter has one-tenth the prevalence of acute atrial fibrillation in the emergency department (ED) but shares many management strategies. Our aim was to compare conversion from acute atrial flutter to sinus rhythm between pharmacological cardioversion followed by electrical cardioversion (Drug-Shock), and electrical cardioversion alone (Shock-Only).

Methods We conducted a randomized, blinded, placebo-controlled comparison of attempted pharmacological cardioversion with IV procainamide followed by electrical cardioversion if necessary, and placebo infusion followed by electrical cardioversion. We enrolled stable patients with a primary diagnosis of acute acute atrial flutter at 11 academic EDs. The primary outcome was conversion to normal sinus rhythm.

Findings From July 2013 to October 2018, we enrolled 76 patients, and none were lost to follow-up. Comparing the Drug-Shock to the Shock-Only group, conversion to sinus rhythm occurred in 33 (100\%) versus 40 (93\%) (absolute difference $7.0 \%$; $95 \% \mathrm{CI}-0.6$ to $14.6 ; P=0.25)$. Median time to conversion from start of infusion in the DrugShock group was 24 min (IQR 21-82) but only 9 (27\%) cases were converted with IV procainamide. Patients in both groups had similar outcomes at 14 days; there were no strokes or deaths.

Interpretation This trial found that the Drug-Shock strategy is potentially superior but that either approach to immediate rhythm control in the ED for patients with acute acute atrial flutter is highly effective, rapid, and safe in restoring sinus rhythm and allowing patients to go home and return to normal activities. Unlike the case of atrial fibrillation, we found that IV procainamide alone was infrequently effective.
\end{abstract}

Keywords Emergency department $\cdot$ Atrial flutter $\cdot$ Cardioversion $\cdot$ Procainamide

\section{Résumé}

Contexte Le flutter auriculaire aigu a un dixième de la prévalence de la fibrillation auriculaire aiguë aux services d'urgence (SU) mais partage de nombreuses stratégies de gestion. Notre objectif était de comparer la conversion du flutter auriculaire aigu en rythme sinusal entre la cardioversion pharmacologique suivie de la cardioversion électrique (Drug-Shock) et la cardioversion électrique seule (Shock-Only).

Supplementary Information The online version contains supplementary material available at https://doi.org/10.1007/s4367 8-020-00067-7.

Ian G. Stiell

istiell@ohri.ca

Extended author information available on the last page of the article 
Méthodes Nous avons effectué une comparaison randomisée, en aveugle et contrôlée par placebo d'une tentative de cardioversion pharmacologique avec le procaïnamide IV suivie d'une cardioversion électrique si nécessaire, et une perfusion de placebo suivie d'une cardioversion électrique. Nous avons inscrit des patients stables avec un diagnostic primaire de flutter auriculaire aigu aigu dans 11 services d'urgence universitaires. Le résultat principal était la conversion à un rythme sinusal normal.

Résultats De juillet 2013 à octobre 2018, nous avons inscrit 76 patients qui ont tous poursuivi le suivi médical jusqu'au terme prévu. En comparant le groupe Drug-Shock au groupe Shock-Only, la conversion au rythme sinusal s'est produite dans 33 (100\%) contre 40 (93\%) (différence absolue 7,0\%; IC à 95\% - 0.6 à 14,6; $P=0,25)$. Le temps médian de conversion depuis le début de la perfusion dans le groupe Drug-Shock était de 24 min (IQR 21-82) mais seulement 9 (27\%) cas ont converti avec le procaïnamide IV. Les patients des deux groupes ont eu des résultats similaires à 14 jours; il n'y a pas eu d'accident vasculaire cérébral ni de décès.

Interprétation Cet essai a révélé que la stratégie Drug-Shock s'est avérée potentiellement supérieure, mais quelle que soit l'approche du contrôle immédiat du rythme cardiaque aux urgences pour les patients atteints de flutter auriculaire aigu aigu, elles sont, tous les deux, très efficaces, rapides et sûres pour rétablir le rythme sinusal et permettre aux patients de rentrer chez eux et reprendre leurs activités normales. Contrairement au cas de la fibrillation auriculaire, nous avons constaté que le procaïnamide IV seul était rarement efficace.

\section{Clinician's capsule}

What is known about the topic?

Acute atrial flutter is less prevalent than acute atrial fibrillation in the emergency department (ED) and few studies have evaluated optimal treatment.

\section{What did this study ask?}

We conducted a randomized, blinded, placebo-controlled comparison between Drug-Shock and ShockOnly strategies for cardioversion for acute atrial flutter in the ED.

\section{What did this study find?}

In 76 patients, conversion to sinus rhythm occurred in $100 \%$ of the Drug-Shock group and $93 \%$ in the Shock-Only group.

Why does this study matter to clinicians?

The Drug-Shock strategy is potentially superior but either approach to ED cardioversion for acute atrial flutter patients is highly effective.

\section{Introduction}

Acute atrial fibrillation and flutter, with onset typically less than $48 \mathrm{~h}$, are the most common arrhythmias requiring treatment in the emergency department (ED) $[1,2]$. Acute atrial flutter is less common with one-tenth the prevalence of acute atrial fibrillation and is characterized by rapid, regular atrial depolarizations [3-5]. We estimate that there are 50,000 acute atrial flutter visits annually to the ED in Canada and the US [6, 7]. Patients typically present with abrupt onset of rapid heart rates of $150 \mathrm{bpm}$ (2:1 conduction) or 100 (3:1 conduction). Most patients with acute

atrial flutter are symptomatic and seek immediate treatment in the ED.

Safe management of acute atrial flutter involves assessment of time of onset and thromboembolic risk factors, making a choice between rhythm or rate control, and determining the need for ongoing oral anticoagulation [8]. Because acute atrial flutter is relatively uncommon, few studies have addressed optimal ED therapy. There is much variation in practice amongst Canadian and US physicians $[9,10]$.

For acute atrial flutter rhythm control in the ED, some physicians prefer to start with antiarrhythmic drugs such as intravenous (IV) procainamide and then move to electrical cardioversion if necessary (Drug-Shock strategy). Others prefer to start immediately with electrical cardioversion (Shock-Only strategy). We have shown that ED physicians are equally divided in their use of the two competing cardioversion strategies $[9,11,12]$. No previous studies have compared these two strategies for acute atrial flutter in the ED and there have been no randomized assessments of IV procainamide for atrial flutter. Our primary aim was to compare conversion to sinus rhythm between the strategies of: (i) attempted pharmacological cardioversion with IV procainamide followed by electrical cardioversion if necessary (Drug-Shock), versus (ii) attempted electrical cardioversion alone (Shock-Only).

\section{Methods}

\section{Design and setting}

This pre-planned and parallel study was conducted concurrently with the separate and larger RAFF2 Trial that employed similar methods for patients with acute atrial fibrillation [13]. We enrolled stable patients with a primary 
diagnosis of acute atrial flutter for whom acute rhythm control was an appropriate option, at 11 academic EDs. We conducted a randomized, blinded, placebo-controlled comparison of: (i) attempted pharmacological cardioversion with IV procainamide $(15 \mathrm{mg} / \mathrm{kg}$ over $30 \mathrm{~min})$ followed by electrical cardioversion $(\geq 200 \mathrm{~J} \times 3)$ if necessary, versus (ii) placebo infusion followed by electrical cardioversion. This was a superiority trial with the two groups allocated $1: 1$ and stratified by study site. (ClinicalTrials. gov: NCT01891058).

\section{Participants}

We included stable patients presenting with an episode of acute atrial flutter of at least $3 \mathrm{~h}$ duration, where symptoms necessitated early management and for whom pharmacological or electrical cardioversion was an appropriate option. Specifically, there was a clear history of: (a) onset within $48 \mathrm{~h}$, or (b) onset within 7 days and adequately anticoagulated for $\geq 4$ weeks (either warfarin with INR $\geq 2.0$ or novel oral anticoagulants), or (c) onset within 7 days and no left atrial thrombus on trans-esophageal echocardiography. Of note, we did not exclude patients with prior episodes of acute atrial flutter, or with valvular heart disease if they were adequately anticoagulated. We excluded patients who were unable to give consent, and were deemed hemodynamically unstable and required immediate cardioversion (hypotension [systolic blood pressure < 100], rapid ventricular pre-excitation, acute coronary syndrome, pulmonary edema), whose primary presentation was for another condition (e.g., pneumonia, pulmonary embolism, sepsis), converted spontaneously prior to randomization, or were previously enrolled in the study. We also excluded patients for a number of potential safety issues (Online Appendix Fig. 1). The electrophysiology cardiologist on the Adjudication Committee blindly reviewed, post hoc, all initial ECGs to verify that the rhythm was atrial flutter.

All participants provided written informed consent and the protocol was approved by the Research Ethics Boards at each site.

\section{Randomization and interventions}

Treating physicians was encouraged to follow Acute Atrial Flutter Management Guidelines (Online Appendix Fig. 2) to ensure standardized assessment, management, use of anticoagulation, and follow-up [14, 15]. On-site research personnel determined allocation by use of an online Electronic Data Capture (EDC) system. The allocation sequence was computer-generated by an independent statistician using a randomly permuted block design of length 8 , stratified by study site. Atrial flutter patients were randomized separately from the atrial fibrillation patients in the larger trial.
Concealment of treatment allocation was assured by use of the password-protected EDC system. Blinding of drug treatment to all research and ED staff was arranged by having local hospital pharmacies that prepare pre-mixed IV bags of either procainamide or placebo, which were placed in locked containers in the ED. These bags were semi-opaque and were only identified by a numeric code.

Patients allocated to the Drug-Shock strategy received a continuous infusion of IV procainamide at a dose of $15 \mathrm{mg} /$ $\mathrm{kg}$, in $500 \mathrm{ml}$ of normal saline solution, given over $30 \mathrm{~min}$ (maximum dose $1,500 \mathrm{mg}$ ). The infusion was stopped if there was conversion to sinus rhythm before the maximum dose. The infusion was discontinued if the corrected QT interval increased $>35 \%$, the QRS interval exceeded $120 \mathrm{~ms}$, or the heart rate dropped below $60 \mathrm{bpm}$. If the systolic blood pressure dropped below $100 \mathrm{mmHg}$, the infusion was interrupted for $15 \mathrm{~min}$ and an IV bolus of 250-ml normal saline administered. If the blood pressure returned to $\geq 100$, the infusion was resumed, if not, it was discontinued. Patients allocated to the Shock-Only strategy received a similar weight-based infusion of normal saline placebo over $30 \mathrm{~min}$. Patients who had not converted to sinus rhythm by $30 \mathrm{~min}$ after the infusion concluded, underwent electrical cardioversion by the attending ED physician.

\section{Outcome measures}

The primary outcome was conversion to and maintenance of sinus rhythm for at least $30 \mathrm{~min}$ at any time following randomization and up to a point immediately following three shocks. Patients who had not converted by the time three shocks had been delivered or who reverted to atrial flutter during the $30 \mathrm{~min}$ following the shocks were deemed treatment failures. We expected few patients to revert back to atrial flutter during the 30-min observation period. Spontaneous conversion after randomization but prior to study interventions was deemed a treatment success. The primary outcome was verified by review of all ECGs by the blinded Adjudication Committee, comprised of two emergency physicians and one electrophysiology cardiologist.

Secondary outcomes evaluated during the ED visit by the research staff were cardiac rhythm at disposition, ED length of stay, and adverse events (attributable to the infusion or electrical cardioversion). Patients were re-assessed in person at 14 days to determine rhythm (by ECG), recurrence of atrial fibrillation, return visits to ED, hospital admissions, stroke, and survival.

\section{Data analysis}

The primary analytical approach was by intention-to-treat. We also conducted a secondary modified intention-to-treat 
analysis that excluded patients who converted to sinus rhythm before the study infusion was started. The primary outcome, conversion to sinus rhythm, was compared between the Drug-Shock and Shock-Only groups using absolute difference between two proportions with 95\% Wald confidence intervals, and statistical significance testing using a chi-squared test. We conducted an adjusted analysis by multivariable logistic regression analysis, adjusted for age, sex, first or repeat episode, time from onset, history of heart failure.

The secondary outcomes were evaluated according to data type: binary outcomes with chi-squared or Fisher's exact test, and continuous data by Student's $t$ test. The independent Data Safety Monitoring Board, at Western University, reviewed any adverse events and enrollment, protocol adherence, data quality, and data completeness every six months. As we compared two standards of care, we did not conduct formal interim outcome analyses.

The sample size was determined by convenience based upon available funding and the enrollment period required for the larger atrial fibrillation trial to reach its total sample size of 396 evaluable patients. We had expected to enroll 50 atrial flutter cases and recognized that we would be underpowered to achieve a minimal clinically importance difference (MCID) of $10 \%$ (absolute) in the conversion rates. As it was, we enrolled 50\% more patients than expected. No subgroup analyses were planned due to the limited sample size.

\section{Results}

Patients were enrolled at 11 different academic EDs in Canada from July 2013 to October 2018. Of 165 eligible patients, 87 refused, 7 were not approached, and 76 were enrolled (Fig. 1). Post hoc adjudication determined that an additional 11 randomized patients were in atrial fibrillation rather than flutter and these cases were excluded. No patients were lost to follow-up for the primary outcome. Patients in the Drug-Shock $(N=33)$ and Shock-Only $(N=43)$ groups were similar but there were some observed differences (Table 1). Patients who had a mean age of 65 years, were $61 \%$ male, $71 \%$ had prior episodes of atrial fibrillation or flutter, and the initial mean ECG heart rate was 121 beats per minute.

Table 2 shows the outcomes for the primary intentionto-treat analyses. Comparing the Drug-Shock to the ShockOnly group, conversion to sinus rhythm occurred in $100 \%$ versus $93 \%$ (absolute difference $7.0 \%$; 95\% CI - 0.6 to 14.6; $P=0.25$ ). No patients reverted back to atrial flutter after the 30-min observation period. While median time to conversion from start of infusion in the Drug-Shock group was 24 min (IQR 21-82), only 9 (27.3\%) cases were converted with IV procainamide. Four patients did not receive the study intervention because they converted spontaneously and were removed from the secondary modified intention-to-treat analysis. This secondary analysis showed no difference for

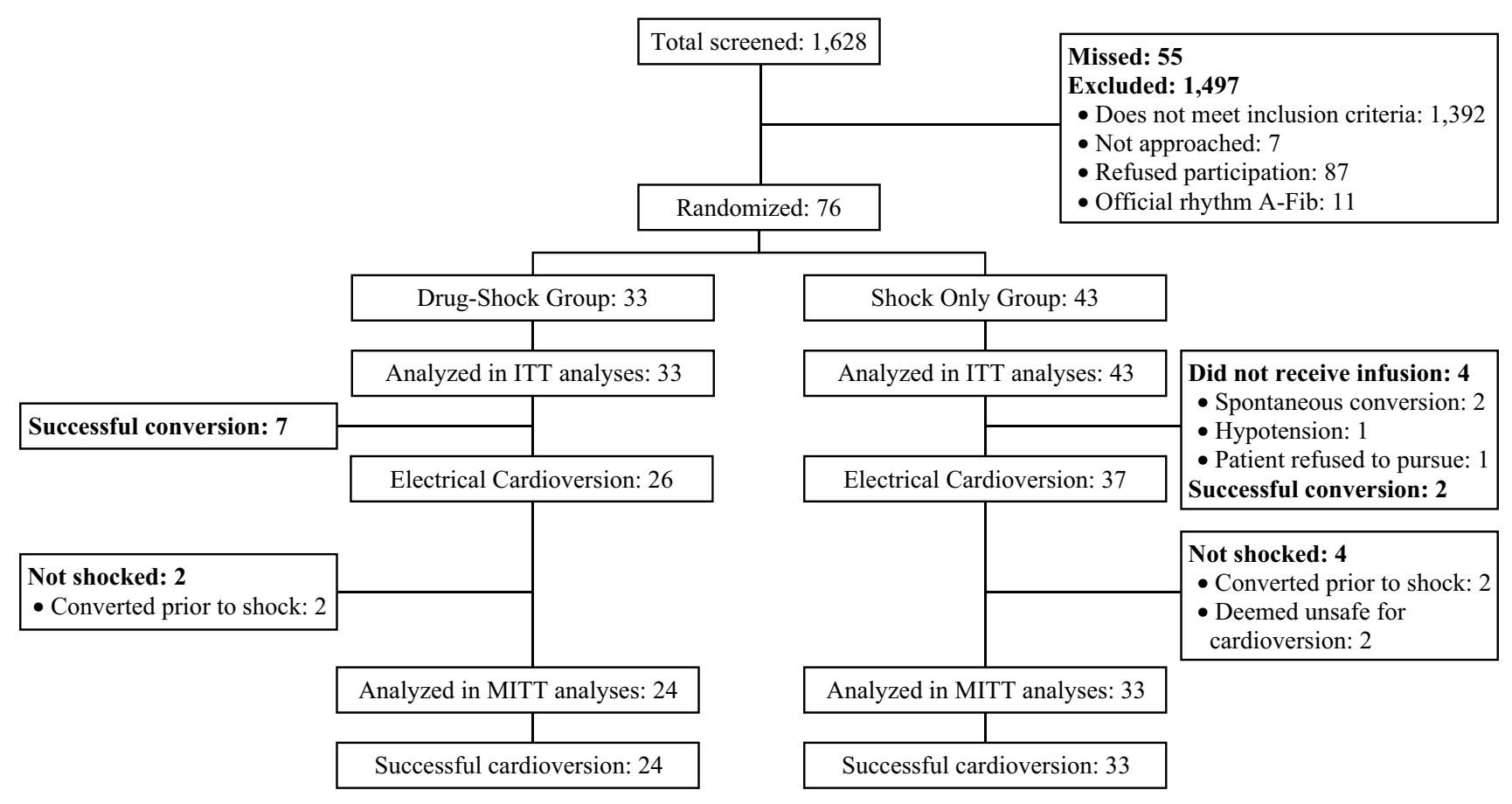

Fig. 1 Trial Profile 
Table 1 Characteristics and ED management for 76 RAFF-2 trial flutter patients

\begin{tabular}{|c|c|c|}
\hline Characteristic & $\begin{array}{l}\text { Drug-Shock } \\
N=33(43.4)\end{array}$ & $\begin{array}{l}\text { Shock-Only } \\
N=43(56.6)\end{array}$ \\
\hline Age in years, mean (SD) & $66.3(13.5)$ & $63.4(12.7)$ \\
\hline Range & 44-92 & $41-95$ \\
\hline Male (\%) & $22(66.7)$ & $24(55.8)$ \\
\hline \multicolumn{3}{|l|}{ Duration of arrhythmia } \\
\hline Median hours (IQR) & $15(10-27)$ & $12(7-35)$ \\
\hline Range & $3-168$ & $3-96$ \\
\hline$<12 \mathrm{~h}(\%)$ & $10(30.3)$ & $20(46.5)$ \\
\hline $12-48$ h $(\%)$ & $19(57.6)$ & $15(34.9)$ \\
\hline$>48 \mathrm{~h}(\%)$ & $4(12.1)$ & $8(18.6)$ \\
\hline \multicolumn{3}{|l|}{ Main presenting symptom (\%) } \\
\hline Palpitations & $29(87.9)$ & $37(86)$ \\
\hline Chest pain & $3(9.1)$ & $2(4.7)$ \\
\hline Shortness of breath & $0(0)$ & $1(2.3)$ \\
\hline Dizziness & $0(0)$ & $2(4.7)$ \\
\hline Weakness & $1(3.0)$ & $1(2.3)$ \\
\hline Other & $0(0)$ & $0(0)$ \\
\hline \multicolumn{3}{|l|}{ Initial vital signs, mean (SD) } \\
\hline Heart Rate & $128.9(25.3)$ & $126(24.6)$ \\
\hline Systolic blood pressure & $129.8(20.8)$ & $133.2(19.2)$ \\
\hline Canadian triage and acuity scale level, median (IQR) & $2(2-3)$ & $2(2-3)$ \\
\hline Previous atrial flutter/fibrillation treatments (\%) & $24(72.7)$ & $30(69.8)$ \\
\hline Electrical cardioversion & $17(51.5)$ & $22(51.2)$ \\
\hline Pharmacologic cardioversion & $8(24.2)$ & $3(7.0)$ \\
\hline Ablation & $8(24.2)$ & $5(11.6)$ \\
\hline \multicolumn{3}{|l|}{$\mathrm{CHADS}_{2}$ criteria $(\%)$} \\
\hline Hypertension & $18(54.5)$ & $19(44.2)$ \\
\hline Age $\geq 75$ years & $9(27.3)$ & $9(20.9)$ \\
\hline Diabetes mellitus & $3(9.1)$ & $6(14.0)$ \\
\hline Stroke/TIA & $1(3.0)$ & $2(4.7)$ \\
\hline Congestive heart failure & $0(0)$ & $0(0)$ \\
\hline \multicolumn{3}{|l|}{$\mathrm{CHADS}_{2}$ score } \\
\hline 0 & $13(39.4)$ & $21(48.8)$ \\
\hline 1 & $9(27.3)$ & $10(23.3)$ \\
\hline$\geq 2$ & $11(33.3)$ & $12(27.9)$ \\
\hline \multicolumn{3}{|l|}{ Other medical history (\%) } \\
\hline Coronary artery disease & $5(15.2)$ & $7(16.3)$ \\
\hline Valvular heart disease & $10(30.3)$ & $3(7.0)$ \\
\hline Pacemaker/ICD & $1(3.0)$ & $0(0)$ \\
\hline COPD/Asthma & $1(3.0)$ & $4(9.3)$ \\
\hline \multicolumn{3}{|l|}{ Current home medications (\%) } \\
\hline Anticoagulants & $16(48.5)$ & $22(51.2)$ \\
\hline Novel anticoagulants & $11(33.3)$ & $15(34.9)$ \\
\hline Warfarin & $5(15.2)$ & $7(16.3)$ \\
\hline Anti-arrhythmics & $0(0)$ & $5(11.6)$ \\
\hline Amiodarone & $0(0)$ & $4(9.3)$ \\
\hline Propafenone & $0(0)$ & $1(2.3)$ \\
\hline Flecainide & $0(0)$ & $0(0)$ \\
\hline Sotalol & $0(0)$ & $0(0)$ \\
\hline Anti-platelet agents & $10(30.3)$ & $10(23.3)$ \\
\hline ASA & $10(30.3)$ & $9(20.9)$ \\
\hline
\end{tabular}


Table 1 (continued)

\begin{tabular}{lll}
\hline Characteristic & Drug-Shock & Shock-Only \\
& $N=33(43.4)$ & $N=43(56.6)$ \\
\hline Clopidogrel & $0(0)$ & $1(2.3)$ \\
Cardiac medications & $22(66.7)$ & $28(65.1)$ \\
Beta-blocker & $18(54.5)$ & $21(48.8)$ \\
Calcium channel blocker & $4(12.1)$ & $7(16.3)$ \\
Investigations $(\%)$ & & \\
Initial ECG-calculated heart rate, mean, (SD) & $122.3(23.3)$ & $121.4(25.4)$ \\
Range & $65-152$ & $65-172$ \\
Chest radiograph shows heart failure & $0(0)$ & $0(0)$ \\
INR, Mean (SD) $(N=138: 127)$ & $1.5(0.7)$ & $1.6(0.9)$ \\
Troponin above 99 th percentile $(N=175 ; 166)$ & $7(28.0)$ & $7(20.0)$ \\
TSH below reference value $(N=86 ; 73)$ & $2(13.3)$ & $1(6.7)$ \\
Transesophageal echocardiography $(\%)$ & $3(9.1)$ & $1(2.3)$ \\
Left atrial clot & $0(0)$ & $0(0)$ \\
Other treatments in ED $(\%)$ & & \\
Rate control agents & $3(9.1)$ & $7(16.3)$ \\
Antithrombotic therapy & $4(12.1)$ & $4(9.3)$ \\
ASA & $0(0)$ & $1(2.3)$ \\
Heparin & $3(9.1)$ & $2(4.7)$ \\
Warfarin & $1(3)$ & $2(4.7)$ \\
Adenosine & $2(6.1)$ & $0(0)$ \\
Other conditions identified while in ED $(\%)$ & & $0(0)$ \\
Congestive heart failure & $0(0)$ & \\
Acute coronary syndrome & $0(0)$ & \\
\hline
\end{tabular}

conversion to sinus rhythm (100\% versus $94.9 \%$; absolute difference 5.1 [ -1.8 to $12.1 \%] ; P=0.50)$. Almost all patients were discharged home ( $100 \%$ versus $95.3 \% ; P=0.50)$.

Adverse events during the infusion were more common in the Drug-Shock group $(24.2 \%$ versus $2.3 \% ; P=0.004)$ but most were transient hypotension (Table 3). Electrical cardioversion was associated with fewer adverse events in the Drug-Shock group (8.3\% versus $24.2 \% ; P=0.08$ ). Overall, no patients suffered death in the ED or subsequent stroke.

Patients were followed for 14 days with similar outcomes in both groups (Table 4). There were no strokes or deaths. Of the $60(78.9 \%)$ patients who returned for an ECG at day 14, $91.7 \%$ were in sinus rhythm. In that time period, few patients required cardioversion in the $\mathrm{ED}(6.1 \%$ versus $11.6 \%)$,

and very few $(3.0 \%$ versus $0 \%)$ required hospital admission.

\section{Discussion}

\section{Interpretation}

This randomized, blinded clinical trial found both the Drug-Shock and Shock-Only strategies were highly effective in safely and quickly returning patients to normal sinus rhythm. Almost all patients were discharged home from the ED, usually within a few hours of cardioversion and, thus, avoided the need for early return to the hospital for follow-up. There was, however, no statistically significant difference between the strategy of attempting chemical cardioversion first and a strategy of proceeding directly to electrical cardioversion for acute atrial flutter patients in the ED although the confidence interval favored Drug-Shock and our MCID of $10 \%$ cannot be ruled out. Because of the small sample size of this parallel study, we can hypothesize that a larger study may have found better outcomes in a Drug-Shock approach. Both drug infusion and electrical cardioversion were associated with adverse events, which generally were not serious. While IV procainamide converted cases quickly, it was directly successful for only $27 \%$ of patients. After 14 days, no patients in either group had suffered a stroke or died, and $92 \%$ of those with a follow-up ECG were still in sinus rhythm. Subsequent ED cardioversions were required for only $9 \%$ of patients and hospital admissions were uncommon. For acute atrial flutter in the ED, physicians should consider a different pharmacological agent than IV procainamide or proceed directly to electrical cardioversion. 
Table 2 Patient outcomes, study interventions, and disposition for 76 RAFF-2 trial flutter patients

\begin{tabular}{|c|c|c|c|c|}
\hline Outcome measure & $\begin{array}{l}\text { Drug-Shock } \\
N=33(43.4)\end{array}$ & $\begin{array}{l}\text { Shock-Only } \\
N=43(56.6)\end{array}$ & $\begin{array}{l}\text { Absolute difference in } \% \\
(95 \% \mathrm{CI})\end{array}$ & $P$ value \\
\hline \multicolumn{5}{|l|}{ Intention-to-treat analysis } \\
\hline \multicolumn{5}{|l|}{ Unadjusted analysis } \\
\hline Converted to normal sinus rhythm & $33(100 \%)$ & $40(93 \%)$ & $7.0(-0.6 ; 14.6)$ & $0.25^{\wedge}$ \\
\hline \multicolumn{5}{|l|}{ Converted by: } \\
\hline Infusion & $9(27.3 \%)$ & $4(9.3 \%)^{* *}$ & & \\
\hline Electrical cardioversion & $24(72.7 \%)$ & $34(79.1 \%)$ & & \\
\hline Spontaneous prior to infusion & $0(0 \%)$ & $2(4.7 \%)$ & & \\
\hline \multicolumn{5}{|l|}{ Disposition } \\
\hline Discharged home from ED & $33(100 \%)$ & $41(95.3 \%)$ & $4.7(-1.6 ; 11.0)$ & $0.50^{\wedge}$ \\
\hline Total ED length of stay, mean hours (SD) & $9.4(8.0)$ & $7.5(4.2)$ & $1.9(-1.2 ; 5.0)$ & $0.23^{+}$ \\
\hline Total patients on anticoagulants at discharge & $19(57.6 \%)$ & $28(65.1 \%)$ & $-7.5(-29.6 ; 14.5)$ & $0.50^{*}$ \\
\hline \multicolumn{5}{|l|}{ Adjusted analysis for conversion } \\
\hline Odds Ratio $(95 \% \mathrm{CI})$ & & & $5.7(0.4 ; 76.0)$ & $0.19^{\#}$ \\
\hline Modified intention-to-treat analysis ${ }^{\S}$ & $N=33$ & $N=39$ & & \\
\hline Converted to normal sinus rhythm & $33(100 \%)$ & $37(94.9 \%)$ & $5.1(-1.8 ; 12.1)$ & $0.50^{\wedge}$ \\
\hline \multicolumn{5}{|l|}{ Disposition } \\
\hline Discharged home from ED & $33(100 \%)$ & $38(97.4 \%)$ & $2.6(-2.4 ; 7.5)$ & $1.00^{\wedge}$ \\
\hline Total ED length of stay, mean hours (SD) & $9.4(8.0)$ & $7.8(4.3)$ & $1.6(-1.5 ; 4.7)$ & $0.31^{+}$ \\
\hline Total patients on anticoagulants at discharge & $19(57.6 \%)$ & $26(66.7 \%)$ & $-9.1(-31.5 ; 13.3)$ & $0.43^{*}$ \\
\hline Details of infusion & $N=33$ & $N=43$ & & \\
\hline Conversion after infusion & $9(27.3 \%)$ & $4(9.3 \%)^{* *}$ & & \\
\hline \multicolumn{5}{|l|}{ Time in minutes, median (IQR): } \\
\hline Arrival to randomization & 177 (101-297) & $170(121-274)$ & & \\
\hline Randomization to infusion started & $18(11-22)$ & $15(9-23)$ & & \\
\hline Start of infusion to conversion & $24(21-82)$ & $60.5(24-76.5)$ & & \\
\hline Details of electrical cardioversion & $N=26$ & $N=37$ & & \\
\hline Shock attempted & $24(72.7 \%)$ & $33(76.7 \%)$ & & \\
\hline Successful conversion $(N=24: 33)$ & $24(100)$ & $33(100)$ & & \\
\hline \multicolumn{5}{|l|}{ Time in minutes, median (IQR) } \\
\hline Infusion stopped to 1 st shock & $62.5(49-76.5)$ & $63(46-75)$ & & \\
\hline
\end{tabular}

*Chi-squared test

** Converted $>30$ min after infusion but prior to electrical cardioversion

${ }^{\wedge}$ Fisher exact test

${ }^{+} t$ test

${ }^{\#} p$ value from random effects multiple logistic regression analysis; adjusted for age, sex, first or repeat episode, time from onset, history of heart failure

$\S_{4}$ patients were excluded for the following reasons: drug not given due to hypotension after randomization (1), patient withdrew consent prior to infusion (1), and spontaneous conversion prior to infusion (2)

\section{Previous studies}

Few studies have examined the management of acute atrial flutter in the ED. A recent meta-analysis of randomized trials of acute atrial fibrillation and flutter concluded that limited data precluded recommendations for atrial flutter treatment [16]. In an observational study of 122 cases of atrial flutter at two EDs, Scheuermeyer found that the majority of patients were discharged home and about half were converted by medication or shock [4]. Several Canadian multicenter ED studies found that the incidence of atrial flutter ranged from 11.7 to $15.3 \%$ of atrial fibrillation cases and that overall discharge rates ranged from 83.3 to $91.0 \%[12,17]$. Our own group documented the effectiveness of IV procainamide for acute atrial flutter to be only $25 \%$ in an observational study of 25 ED patients, with $100 \%$ of resistant cases undergoing successful electrical cardioversion [18]. Several small observational studies found IV 
Table 3 Adverse events while in the ED

\begin{tabular}{|c|c|c|c|}
\hline Outcome measure & $\begin{array}{l}\text { Drug-Shock } \\
N=33(43.4)\end{array}$ & $\begin{array}{l}\text { Shock-Only } \\
N=43(56.6)\end{array}$ & $P$ value \\
\hline Adverse event during or after infusion & $8(24.2)$ & $1(2.3)$ & 0.004 \\
\hline Infusion discontinued $^{\mathrm{a}}$ & $3(9.1)$ & $0(0)$ & \\
\hline Urgent electrical cardioversion & $1(3.0)$ & $0(0)$ & \\
\hline Hypotension $(\mathrm{SBP}<90)$ & $5(15.2)$ & $1(2.3)$ & \\
\hline Other events & $5(15.2)$ & $0(0)$ & \\
\hline Bradycardia $(\mathrm{HR}<50)$ & $1(3.0)$ & $0(0)$ & \\
\hline Tachyarrhythmia & $2(6.0)$ & $0(0)$ & \\
\hline SVT & $1(3.0)$ & $0(0)$ & \\
\hline Dizziness & $1(3.0)$ & $0(0)$ & \\
\hline $\begin{array}{l}\text { Adverse event during or after electrical cardio- } \\
\text { version }(N=24: 33)\end{array}$ & $2(8.3)$ & $8(24.2)$ & 0.08 \\
\hline Hypoxia & $0(0)$ & $1(3.0)$ & \\
\hline Airway maneuvers applied & $2(8.3)$ & $9(27.3)$ & \\
\hline
\end{tabular}

Patients may have had more than one event

${ }^{a}$ Discontinued due to hypotension (1), tachyarrhythmia (2)
Table 4 14-Day Follow-up for 76 recent-onset flutter patients

\begin{tabular}{|c|c|c|}
\hline Characteristic & $\begin{array}{l}\text { Drug-Shock } \\
N=33(43.4)\end{array}$ & $\begin{array}{l}\text { Shock only } \\
N=43(56.6)\end{array}$ \\
\hline Death $(\%)$ & $0(0)$ & $0(0)$ \\
\hline Stroke $(\%)$ & $0(0)$ & $0(0)$ \\
\hline 14-day follow-up visit (\%) & $31(93.9)$ & $41(95.3)$ \\
\hline In person & $27(81.8)$ & $37(86.0)$ \\
\hline By telephone & $4(12.1)$ & $4(9.3)$ \\
\hline ECG at day $14(\%)$ & $25(75.8)$ & $35(81.4)$ \\
\hline Heart rate, mean (SD) ( $N=141: 154)$ & $69.6(17.1)$ & $66.8(18.2)$ \\
\hline Normal sinus $(N=148: 157)$ & $23(92.0)$ & $32(91.4)$ \\
\hline Atrial fibrillation ( $N=148: 157$ ) & $0(0)$ & $1(2.9)$ \\
\hline Atrial flutter ( $N=148: 157)$ & $2(8.0)$ & $2(5.7)$ \\
\hline Return ED visit (\%) & $7(21.2)$ & $8(18.6)$ \\
\hline Related to AF/AFL & $7(21.2)$ & $6(14.0)$ \\
\hline Outpatient visits (\%) & $18(54.5)$ & $17(39.5)$ \\
\hline Cardiology & $11(33.3)$ & $12(27.9)$ \\
\hline Internal medicine & $1(3.0)$ & $0(0)$ \\
\hline Family physician & $8(24.2)$ & $6(14.0)$ \\
\hline Hospital admission (\%) & $1(3.0)$ & $0(0)$ \\
\hline Related to AF/AFL & $1(3.0)$ & $0(0)$ \\
\hline $\begin{array}{l}\text { Subsequent electrical cardioversion } \\
(\%)\end{array}$ & $2(6.1)$ & 5 (11.6) \\
\hline Days post ED, mean (SD) & $10(5.7)$ & $5.4(5.9)$ \\
\hline In emergency department & $2(6.1)$ & $5(11.6)$ \\
\hline In clinic & $0(0)$ & $0(0)$ \\
\hline Transthoracic echocardiography (\%) & $3(9.1)$ & $3(7.0)$ \\
\hline
\end{tabular}

ibutilide better than IV amiodarone for atrial flutter with conversion rates ranging from 75 to $90 \%$ but none compared to IV procainamide [19-21].

\section{Limitations}

A major issue is the small sample size which precluded definitive findings. Nevertheless, this was the largest clinical trial of ED atrial flutter to date and the sample required to assess an MCID of $10 \%$ would require four times the number of sites that we used. In addition, and despite blocked randomization, the study groups differed in some characteristics. The allocation scheme was stratified by site and in blocks of eight and we believe that many of the blocks were not filled, leading to imbalance. In hindsight, we could have used smaller blocks.

Another issue is that 11 randomized patients were identified post hoc as being in atrial fibrillation rather than flutter and were excluded. We defend this by saying that the excluded patients did not have the condition of interest in the trial and their inclusion would have confounded the findings.

We acknowledge that we missed eligible patients because research staff could not always be present during off hours. While the 14-day follow-up could have missed subsequent thromboembolic events, our ongoing 6- and 12-month follow-ups have not shown this to be the case to date.

\section{Implications}

The most important finding from this study is that, similar to atrial fibrillation, immediate ED rhythm control leads to a very high proportion of atrial flutter patients being discharged in sinus rhythm without serious adverse events. Patients can be rapidly cardioverted in the ED, resolving their acute symptoms and enabling discharge home. This avoids unnecessary hospital admission or next-day re-evaluation by cardiology. This obviates the need for rate control 
medication prescriptions. Meanwhile, patients can quickly return to normal activities and avoid prolonged lengths of stay in crowded EDs. Nevertheless, the choice between pharmacological and electrical cardioversion should be a shared decision between the patient and the physician. Our study provides data to assist physicians in these discussions.

We noted that physicians misinterpreted atrial fibrillation as atrial flutter surprisingly often. This highlights that ED physicians have some difficulty in distinguishing atrial fibrillation with intermittent flutter waves from true atrial flutter. Fortunately, management with procainamide and/ or electrical cardioversion works well for both arrhythmias.

Pharmacological cardioversion has the advantage of allowing physicians to attend to other patients during the drug infusion. It also frequently avoids the need for procedural sedation, which may lead to serious adverse events. Electrical cardioversion also requires explicit consent and the continuous attendance of additional healthcare providers. We showed that the Drug-Shock strategy is potentially superior to a Shock-Only approach. Unlike the case with atrial fibrillation, we found that IV procainamide is directly effective in only about one-quarter of acute atrial flutter cases. For stable patients, both the US and the European guidelines recommend IV ibutilide, although this drug carries a small risk of torsades de pointes and should be avoided in the presence of a prolonged QT interval [3, 22].

Three issues are important for ED physicians managing acute atrial flutter. When faced with a regular and narrow-complex tachycardia, it may be difficult for clinicians to distinguish between atrial flutter with 2:1 block and supraventricular tachycardia. Current guidelines recommend an attempt at vagal maneuvers or adenosine, and then to consider calcium channel or beta blockers [23]. When faced with an uncertain regular wide-complex tachycardia, physicians should choose electrical cardioversion or, in stable patients, vagal maneuvers, adenosine, procainamide, and/or ibutilide. Stroke prevention is an essential element in the management of acute fibrillation and flutter in the ED. Recent guideline changes apply equally to both arrhythmias and consider the safety of cardioversion as well as the need for post-discharge anticoagulation $[24,25]$. Physicians should be familiar with current recommendations [26]. Future studies may compare the relative effectiveness and safety of managing acute atrial flutter with electrical cardioversion versus other drugs.

\section{Conclusion}

This clinical trial found that the Drug-Shock strategy is potentially superior but that either approach to immediate rhythm control in the ED for patients with acute atrial flutter is highly effective, rapid, and safe in restoring sinus rhythm and allowing patients to go home and return to normal activities. Unlike the case of atrial fibrillation, we found that IV procainamide was not very effective directly. Our study provides data to assist with shared decision-making between patients and physicians. Immediate rhythm control for ED patients with acute atrial flutter leads to excellent outcomes.

Acknowledgements We gratefully acknowledge the invaluable assistance of the following individuals from the study sites: Hôpital de l'Enfant-Jésus (Quebec, Quebec): Suzy Lavoie, RN; Institut de Cardiologie de Montréal (Montreal, Quebec): Véronique Roy, RN; Hôpital du Sacré-Coeur de Montréal (Montreal, Quebec): Chantal Lanthier, RN; Kingston Health Sciences Centre (Kingston, Ontario): Nicole O'Callaghan, MSc, Vlad Latiu, MD; Mount Sinai Hospital (Toronto, Ontario): Shelley McLeod, MSc, Cameron Thompson, MSc; Foothills Medical Centre (Calgary, Alberta): Heidi Boyda, PhD, Tristan Holotnak, BSc, MPH, Katrina Koger, BSc; University of Alberta Hospital (Edmonton, Alberta): Natalie Runham, RN, Pamela Pang, RN; Vancouver General Hospital: Vi Ho, MD, Rupinder Brar, MD. In addition, we thank the following individuals from the coordinating centre in Ottawa, Ontario: Ottawa Hospital Research Institute: Angela Marcantonio, Tami Clavet RN, Maureen Lowe RN, Elias Horner, Kelsey Seal, Laura Salter, Kassidy Rideout, Matthew Lukasik, Emma Lee, and James-Jules Linton; Ottawa Methods Centre: My-Linh Tran, Helen Wang, and Dong Vo. We are also very grateful to the hundreds of ED nurses and physicians whose efforts made this project very successful.

Author contributions The author contributions were as follows: IS and JP conceived the idea and prepared the manuscript and secured research funding. $\mathrm{CC}$ managed the budget, contracts, and personnel. JB coordinated the study and supervised data collection. JB, and EB supervised in the recruitment of patients and management of data. MT and M-JN conducted the statistical analyses. All authors supervised the conduct of the trial and data collection or drafted the manuscript and/or contributed to its revision, and all approved the final version. IS is guarantor.

Funding This study was funded by peer-reviewed grants from the Heart and Stroke Foundation of Canada (G-13-0002756) and the Canadian Institutes of Health Research (MOP-142226). ClinicalTrials.gov Identifier: NCT01891058; Sponsor: Ottawa Hospital Research Institute. Dr. Perry is supported by a Mid-Career Investigator Award from the Heart and Stroke Foundation of Ontario. Dr. Hohl is supported by a Michael Smith Foundation Health Professional Investigator award. Dr. Thiruganasambandamoorthy was supported by a Heart and Stroke National New Investigator Award and is currently supported by Physician' Services Incorporated Foundation Mid-Career Clinical Researcher Award. The funding agencies had no role in the study design, collection, analysis, or manuscript preparation. Peer-reviewed grants from Heart and Stroke Foundation of Canada and the Canadian Institutes of Health Research.

\section{Compliance with ethical standards}

Conflict of interest All authors have completed the ICMJE uniform disclosure form at www.icmje.org/coi_disclosure.pdf and declare: no support from any organization for the submitted work; no financial relationships with any organizations that might have an interest in the submitted work in the previous three years; no other relationships or activities that could appear to have influenced the submitted work.

Data sharing We do not have consent from patients or hospital research ethics boards to share individual case data. We will, however, make summary data available to corresponding investigators. 


\section{References}

1. Connors S, Dorian P. Management of supraventricular tachycardia in the emergency department. Can J Cardiol. 1997;13(Suppl A):19A-24A

2. Michael JA, Stiell IGSA, et al. Cardioversion of paroxysmal atrial fibrillation in the emergency department. Ann Emerg Med. 1999;33:379-87.

3. Kirchhof P, Benussi S, Kotecha D, et al. 2016 ESC Guidelines for the management of atrial fibrillation developed in collaboration with EACTS. Eur Heart J. 2016;37(38):2893-962.

4. Scheuermeyer FX, Grafstein E, Heilbron B, et al. Emergency department management and 1-year outcomes of patients with atrial flutter. Ann Emerg Med. 2011;57(6):564-71.

5. Hamilton A, Clark D, Gray A, et al. The epidemiology and management of recent-onset atrial fibrillation and flutter presenting to the Emergency Department. Eur J Emerg Med. 2015;22(3):15561. https://doi.org/10.1097/mej.0000000000000198[publishedO nlineFirst:2014/09/10].

6. Pitts SR, Niska RW, Xu J, et al. National Hospital Ambulatory Medical Care Survey: 2006 emergency department summary. Natl Health Stat Report. 2008;7:1-38.

7. Chan TB, Schull MJ, Schultz SE. Emergency department services in Ontario 1993-2000. Toronto: Institute for Clinical Evaluative Sciences; 2001.

8. Stiell IG, Scheuermeyer FX, Vadeboncoeur A, et al. CAEP Acute atrial fibrillation/Flutter Best Practices Checklist. Can J Emerg Med. 2018;20(3):334-42.

9. Stiell IG, Clement CM, Brison RJ, et al. Variation in management of recent-onset atrial fibrillation and flutter among academic hospital emergency departments. Ann Emerg Med. 2011;57(1):13-21.

10. Rozen G, Hosseini SM, Kaadan MI, et al. Emergency department visits for atrial fibrillation in the United States: trends in admission rates and economic burden From 2007 to 2014. J Am Heart Assoc 2018; 7(15)

11. Rogenstein C, Kelly AM, Mason S, et al. An international view of how recent-onset atrial fibrillation is treated in the emergency department. Acad Emerg Med. 2012;19:1255-60.

12. Stiell IG, Clement CM, Rowe BH, et al. Outcomes for ED patients with recent-onset Atrial Fibrillation and Flutter (RAFF) treated in Canadian Hospitals. Ann Emerg Med. 2017;69(5):562-71.

13. Stiell IG, Sivilotti MLA, Taljaard M, et al. Electrical versus pharmacological cardioversion for emergency department patients with acute atrial fibrillation (RAFF2): a partial factorial randomised trial. Lancet. 2020;395(10221):339-49. https:// doi.org/10.1016/s0140-6736(19)32994-0[publishedOnlineFirst :2020/02/03].

14. Stiell IG, Macle L. Canadian cardiovascular society atrial fibrillation guidelines 2010: management of recent-onset atrial fibrillation and flutter in the emergency department. Can J Cardiol. 2011;27(1):38-46.

15. Verma A, Cairns JA, Mitchell LB, et al. 2014 focused update of the canadian cardiovascular society guidelines for the management of atrial fibrillation. Can J Cardiol. 2014;30(10):1114-30.

16. deSouza IS, Tadrous M, Sexton T, et al. Pharmacologic cardioversion of recent-onset atrial fibrillation and flutter in the emergency department: a systematic review and network meta-analysis. Ann Emerg Med. 2020. https://doi.org/10.1016/j.annemergme d.2020.01.013[publishedOnlineFirst:2020/03/17].

17. Stiell IG, Birnie D. Managing recent-onset atrial fibrillation in the emergency department. Ann Emerg Med. 2011;57(1):31-2.

18. Stiell IG, Clement C, Symington C, et al. Emergency department use of intravenous procainamide for patients with acute atrial fibrillation or flutter. Acad Emerg Med. 2007;14:1158-64.

19. Mountantonakis SE, Moutzouris DA, Tiu RV, et al. Ibutilide to expedite ED therapy for recent-onset atrial fibrillation flutter. Am J Emerg Med. 2006;24:407-12.

20. Kafkas NV, Patsilinakos SP, Mertzanos GA, et al. Conversion efficacy of intravenous ibutilide compared with intravenous amiodarone in patients with recent-onset atrial fibrillation and atrial flutter. Int J Cardiol. 2007;118(3):321-5. https://doi.org/10.1016/j. ijcard.2006.07.017[publishedOnlineFirst:2006/10/20].

21. Vinson DR, Lugovskaya N, Warton EM, et al. Ibutilide effectiveness and safety in the cardioversion of atrial fibrillation and flutter in the Community Emergency Department. Ann Emerg Med. 2018;71(1):96-108.e2. https://doi.org/10.1016/j.annemergme d.2017.07.481[publishedOnlineFirst:2017/10/04].

22. January CT, Wann LS, Alpert JS, et al. 2014 AHA/ACC/HRS Guideline for the management of patients with atrial fibrillation: a report of the American College of Cardiology/American Heart Association Task Force on Practice Guidelines and the Heart Rhythm Society. Circulation. 2014;130(23):e199-267. https:// doi.org/10.1161/CIR.0000000000000041

23. Brugada J, Katritsis DG, Arbelo E, et al. 2019 ESC Guidelines for the management of patients with supraventricular tachycardia The Task Force for the management of patients with supraventricular tachycardia of the European Society of Cardiology (ESC). Eur Heart J. 2020;41(5):655-720. https://doi.org/10.1093/eurheartj/ ehz467[publishedOnlineFirst:2019/09/11].

24. Andrade JG, Verma A, Mitchell LB, et al. 2018 Focused Update of the Canadian Cardiovascular Society guidelines for the management of atrial fibrillation. Can J Cardiol. 2018;34(11):1371-92.

25. Stiell IG, McMurtry MS, McRae A, et al. Safe cardioversion for patients with acute-onset atrial fibrillation and flutter: practical concerns and considerations. Can J Cardiol 2019; (in Press)

26. Stiell IG, McMurtry MS, McRae A, et al. The Canadian Cardiovascular Society 2018 guideline update for atrial fibrillationa different perspective. Cjem. 2019;21(5):572-5. https://doi. org/10.1017/cem.2019.399[publishedOnlineFirst:2019/09/26].

\section{Authors and Affiliations}

\section{Ian G. Stiell ${ }^{1,2} \cdot$ Marco L. A. Sivilotti $^{3} \cdot$ Monica Taljaard $^{4} \cdot$ David Birnie $^{5} \cdot$ Alain Vadeboncoeur $^{6}$. Corinne M. Hohl ${ }^{7}$. Andrew D. McRae ${ }^{8} \cdot$ Judy Morris $^{10}$ - Eric Mercier ${ }^{12} \cdot$ Laurent Macle $^{6} \cdot$ Robert J. Brison $^{3}$. Venkatesh Thiruganasambandamoorthy ${ }^{1,2} \cdot$ Brian H. Rowe $^{9} \cdot$ Bjug Borgundvaag $^{11}$. Catherine M. Clement ${ }^{13}$. Jennifer Brinkhurst ${ }^{13} \cdot$ Erica Brown $^{13} \cdot$ Marie-Joe Nemnom $^{13} \cdot$ George A. Wells $^{14}$. Jeffrey J. Perry ${ }^{1,2}$}

1 Department of Emergency Medicine, University of Ottawa, Ottawa, ON, Canada
2 Clinical Epidemiology Program, Ottawa Hospital Research Institute, Ottawa, ON, Canada 
3 Department of Emergency Medicine, Queen's University, Kingston, ON, Canada

4 Clinical Epidemiology Program, Ottawa Hospital Research Institute, School of Epidemiology and Public Health, University of Ottawa, Ottawa, ON, Canada

5 Division of Cardiology, University of Ottawa Heart Institute, University of Ottawa, Ottawa, ON, Canada

6 Institut de Cardiologie de Montréal, Université de Montréal, Montréal, QC, Canada

7 Department of Emergency Medicine, Centre for Clinical Epidemiology and Evaluation, Vancouver Coastal Health Research Institute, University of British Columbia, Vancouver, BC, Canada

8 Department of Emergency Medicine and Community Health Sciences, University of Calgary, Calgary, AB, Canada

9 Department of Emergency Medicine and School of Public Health, University of Alberta, Edmonton, AB, Canada
10 Department of Family Medicine and Emergency Medicine, Université de Montréal, Montréal, QC, Canada

11 Division of Emergency Medicine, Schwartz/Reisman Emergency Medicine Institute, Mount Sinai Hospital, University of Toronto, Toronto, ON, Canada

12 Department of Family Medicine and Emergency Medicine, Centre de Recherche du CHU de Québec, Université Laval, Québec, QC, Canada

13 Clinical Epidemiology Program, Ottawa Hospital Research Institute, University of Ottawa, Ottawa, ON, Canada

14 University of Ottawa Heart Institute, University of Ottawa, Ottawa, ON, Canada 